\title{
Ser sí mismo auténtico. Existencia, facticidad e instante
}

\author{
The authentic self. Existence, facticity and instant
}

MARÍA CIELO AUCAR

(CONICET)

\begin{abstract}
Resumen: Desde una perspectiva ontológico-existencial, el artículo pretende poner en evidencia algunos de los rasgos constitutivos del ser sí mismo auténtico en el pensamiento de Søren Kierkegaard y su respectiva recepción en la obra temprana de Martin Heidegger, específicamente Sein und Zeit. Para ello se propone, en primer lugar, llevar a cabo el análisis fenomenológico-hermenéutico de la noción kierkegaardiana de sí mismo como espíritu, así como de la noción heideggeriana de Dasein, para concluir en un diálogo crítico-hermenéutico entre ambos pensadores en torno a tal cuestión.

Palabras Clave: sí mismo, autenticidad, existencia, facticidad, instante
\end{abstract}

\begin{abstract}
From an ontological-existential perspective, this article pretends to highlight some of the constitutive features of the authentic self in the thought of Søren Kierkegaard and its respective reception in the early work of Martin Heidegger, specifically Sein und Zeit. To do this, it is proposed, first of all, to carry out the phenomenological-hermeneutical analysis of the Kierkegaardian notion of oneself as spirit, as well as the Heideggerian notion of Dasein, to conclude in a critical-hermeneutical dialogue between both thinkers around this question.
\end{abstract}

Keywords: self, authenticity, existence, facticity, instant

\section{Introducción}

La cuestión del sí mismo ha sido desde siempre una de las más relevantes en el ámbito de la filosofía, a la vez que una de las más interpelantes, en tanto nos cuestiona desde lo más profundo de nuestro ser. Søren Kierkegaard y Martin Heidegger han sido dos de los pensadores más influyentes del siglo XIX y XX, respectivamente. Ambos han sabido articular de una forma sensata y perspicaz los elementos que configuran el ser del ser sí mismo. Este artículo tiene como objetivo evidenciar aquellos elementos que constituyen el fundamento originario del ser sí mismo auténtico dilucidados en algunas de las obras pseudónimas de Kierkegaard -O lo uno o lo otro, Migajas filosóficas, El concepto de la angustia, Postscriptum y La enfermedad mortal-, así como su correspondiente recepción en la obra temprana de Heidegger, Ser y tiempo, poniendo en diálogo a ambos pensadores en torno de la cuestión que nos ocupa. 
El análisis ha sido realizado desde una perspectiva fenomenológico-hermenéutica externa. Con esto quiero decir que, si bien he basado mis investigaciones en la comprensión kierkegaardiana del ser sí mismo auténtico y su recepción heideggeriana, he procurado ser fiel al criterio metodológico kierkegaardiano según el cual «se deja al lector que por cuenta propia ate cabos, por así decirlo, pues nada se hace para comodidad del lector» (Kierkegaard, 2008, p. 300). Por lo que he decidido no anclar mi investigación en una exégesis preponderantemente filológica y posterior comparación entre los desarrollos de ambos pensadores, sino, antes bien, ordenarla según el conjunto de interrogantes que me han surgido durante la lectura de dichas obras. Tales interrogantes actúan, pues, como eje interpretativo en torno del cual se articula el bosquejo de una comprensión propia de los temas analizados.

El punto de partida de la investigación ha estado dado por las comprensiones kierkegaardiana y heideggeriana de la noción del ser sí mismo como espíritu y Dasein, respectivamente. Haciendo uso de un lenguaje propio de lo que él mismo en El concepto de la angustia denomina «psicología», Kierkegaard nos introduce a la noción de espíritu como síntesis de distintas facultades del existir que se contraponen sin contradecirse y que configuran el fundamento del ser sí mismo. Por su parte, desde una perspectiva ontológico-fundamental, Heidegger, lector de Kierkegaard ${ }^{1}$, nos acerca a la noción de Dasein como lugar en el que el ser se manifiesta, como el único ser capaz de comprenderse a sí mismo a través del modo en que comprende su relación con los entes del mundo.

Heidegger acepta la precedencia de Kierkegaard en el tratamiento de la existencia como el modo de ser específico del hombre. No es posible comprender el encuadre ontológico heideggeriano sin haber recorrido antes el abordaje que Kierkegaard hace de la existencia y que desarrolla en el Postscriptum, obra en la que intenta claramente determinar el ser y la constitución de la existencia en tanto tal y, por tanto, pensarla también y anticipadamente en términos ontológicos. Esto deja en evidencia que, en cuanto al grado de primordialidad, Kierkegaard es condición del desarrollo y de la determinación ontológica que hace Heidegger de la noción de existencia y, consecuentemente también, del rol que en esa determinación cumplen la facticidad y el instante. A mi modo de ver, el modo en que Heidegger comprende la noción de existencia y las de facticidad e instante como existenciarios constitutivos del sí mismo auténtico, son imposibles de comprender plenamente sin presuponer en su génesis los desarrollos kierkegaardianos.

Sin embargo, las significaciones a las que remiten la autenticidad kierkegaardiana y la autenticidad heideggeriana no son superponibles. Ambas merecen un análisis separado que invite luego a una posterior puesta en diálogo.

\section{Ser sí mismo como espíritu y posibilidad}

\subsection{El existente singular}

Para poder acceder a una mejor comprensión del ser del ser sí mismo kierkegaardiano es necesario tener claridad respecto de las siguientes cuestiones. El abordaje existencial del ser sí mismo que Kierkegaard realiza implica el reemplazo de la concepción clásica del sujeto como sustancia genérica - que recibe su esencia por anticipado-,

En su conferencia durante el semestre de invierno de 1921/22, Heidegger cita cierto pasaje de los escritos de A de $O$ lo uno o lo otro: «Lo difícil para la filosofía y el filósofo es detenerse» (GA 65, p. 182). 
por un individuo singular y concreto, por "este" y no otro individuo, que hace ser su propio ser en el tiempo. En este sentido, esta perspectiva supone la comprensión de un existente cuya existencia consiste en llegar a ser quien es eligiéndose a sí a través del modo en que se relaciona consigo mismo y con lo otro que sí. De este modo, frente a una concepción sustancialista, genérica, a-histórica y esencialista, el danés plantea una nueva perspectiva: la del existente singular, cuya esencia no está dada por anticipado, sino que llega a ser temporalmente y tiene su origen en la relación del sí mismo consigo mismo y con el mundo. Ya no se trataría -insisto- de un sí mismo atemporal y genérico, sino de una síntesis relacional, históricamente aconteciente, que sólo es posible desde la comprensión kierkegaardiana del sí mismo como espíritu.

\subsection{Ser sí mismo como espíritu}

Para Kierkegaard, ser sí mismo es ser espíritu. Pero, ¿qué es, acaso, el espíritu? En una de sus más célebres citas de La enfermedad mortal Kierkegaard es claro al respecto: «El hombre es espíritu. Pero, ¿qué es el espíritu? El espíritu es el yo. Pero ¿qué es el yo? El yo es una relación que se relaciona a sí misma, o bien es lo que, en la relación, hace que ésta se relacione consigo misma» (Kierkegaard, 2008, p. 33). Desde una perspectiva ontológico-fundamental, el espíritu [Selbst] es relación. Que el espíritu sea concebido como una relación que se relaciona consigo misma significa que el existente es capaz de volverse sobre sí y elegirse - o no- de acuerdo al modo en que se relaciona con los demás existentes y con el mundo. En otros términos, eligiendo el modo de relacionarse con los otros y con el mundo, el sí mismo elige relacionarse de un cierto modo a sí mismo y elegirse a sí, aunque fuese en el modo negativo de elegir no asumir su condición espiritual y no relacionarse a sí en su relación con lo otro, lo que caracteriza al nivel inferior de existencia que Kierkegaard denomina "estético". Tal como Annemarie Pieper señala, para Kierkegaard, «existir significa relacionarse a sí» (Pieper, 2014, p. 38), entendiendo el «relacionarse a sí»» no como un acto reactivo frente a la acción de lo otro, sino más bien como una actividad que supone mi relación con lo otro y con los otros en función de la cual me comprendo a mí mismo. Si tomáramos el ejemplo de un músico, podríamos decir que el músico que se relaciona con el mundo de la música desde su condición de espíritu, no sólo se relaciona de cierto modo con este mundo, sino que, haciéndolo, se elige a sí mismo como músico. Es decir, eligiendo el modo de relacionarse con la música -lo otro que sí-, el músico se elige a sí mismo como tal. Por lo tanto, podríamos decir que no es espíritu aquel individuo que interpreta cierta obra musical y se relaciona con el mundo de la música de cierto modo, sino que es espíritu aquel que se determina a sí mismo como músico al relacionarse con el mundo de la música por medio de un cierto modo de interpretar melodías musicales. Además, esta relación que el sí mismo es, no es atemporal y absoluta, sino que está arraigada a la propia historicidad y particularidad del existente. El ser sí mismo es relación consigo mismo, pero no como una relación que está dada de una vez y para siempre, sino como aquella que debe hacerse a cada instante en la existencia concreta y particular, es decir, desde la propia historicidad.

Comprender al sí mismo como espíritu, esto es, como un ser que elige, asume y realiza históricamente su ser, relacionándose con éste, su ser, significa, también, comprenderlo como aquel ser al cual le es posible existir de manera auténtica (o inauténtica). En efecto, a diferencia de otro seres cósicos, el espíritu tiene la posibilidad de existir como espíritu y no está determinado a realizar una esencia prefijada. En El concepto de la 
angustia, Haufniensis sostiene que «la realidad del espíritu está siempre mostrándose como una figura que tienta su posibilidad» (Kierkegaard, 2016a, p. 159). Pero, ¿en qué consiste la posibilidad? Para el danés, «la posibilidad consiste en que se puede» (Kierkegaard, 2016a, p. 166). Que la posibilidad consista en que se puede quiere decir que, en un sentido originario, antes de poder elegir entre una opción u otra, el espíritu es aquel que puede elegirse a sí a través del modo en que comprende el mundo. En un plano ontológico fundamental, la libertad no es comprendida por Haufniensis como libre albedrío [liberum arbitrium], sino más bien como la posibilidad de poder por la que el espíritu puede elegirse a sí mismo y asumir su condición espiritual a través de su relación con los entes del mundo.

El existente que deviene espíritu es, entonces, aquel que elige existir de manera auténtica por la elección que hace de sí mismo en el instante que le sobreviene y en el que elige sus posibilidades más propias. ¿Cuáles son esas posibilidades? Aquellas que lo realizan históricamente en su particularidad, es decir, aquellas posibilidades que no meramente lo distraen y lo hacen saltar de una posibilidad a otra diferente e irrelativa, sin vínculo intrínseco con las anteriores, sino que lo van constituyendo como un quién particular con una continuidad histórica. Ser sí mismo es tener una historia de posibilidades entrelazadas que se continúan y se articulan en una situación que se va desplegando temporalmente.

\subsection{Ser sí mismo como síntesis}

Pero la comprensión kierkegaardiana del ser sí mismo auténtico no se agota en su concepción del ser espíritu como elección de sí a través de su relación a las posibilidades que le resultan más propias. Ser sí mismo auténtico es también ser síntesis. Veamos, entonces, a qué se refiere nuestro autor al sostener que ser sí mismo es ser síntesis.

Para Kierkegaard, el sí mismo es síntesis entre distintas funciones del existir. En $\mathrm{El}$ concepto de la angustia, Haufniensis sostiene que «el hombre es una síntesis de cuerpo y alma constituida y sostenida por el espíritu» (Kierkegaard, 2016a, p. 198). El espíritu sintetiza las impresiones del alma -las configura como siendo tales o cuales sensaciones y las determina como propias, como pertenecientes a sí mismo- que resultan de la actividad de nuestro propio cuerpo y, por lo tanto, se relaciona con ellas de un modo o de otro, es decir, las interpreta en el marco de una u otra posibilidad de ser. De allí se deriva que el existente no sea cuerpo ni alma, sino síntesis de cuerpo y alma puesta por el espíritu: «alma y cuerpo eran los dos momentos de la síntesis, y el espíritu, el tercero» (Kierkegaard, 2016a, p. 198). Que la síntesis de cuerpo y alma sea sostenida por el espíritu significa que el espíritu conjuga o sintetiza a ambos -el cuerpo físico y el alma- en el sí mismo, que precisamente es posibilidad de ser. El espíritu determina el modo en que cuerpo y alma se sintetizan en el sí mismo que él es. Por eso el espíritu no es una nueva sustancia que contenga a las otras dos, sino pura actualidad o ejecución. El espíritu no es una tercera sustancia ontológica general que contiene y supera a las otras dos -cuerpo y alma-, sino que es estrictamente individual, tal como lo constata Ringleben:

"Espíritu es el yo". Ella refiere lo siguiente: el espíritu no es algo supraindividual, en lo cual el hombre particular meramente participa, sino que el espíritu existe (en todo caso así lo hace en el humano) sólo como ipseidad. El espíritu es el ser sí mismo del hombre respectivamente particular [...], pues en el caso del hombre sólo se da el espíritu asumido por el sí mismo, vuelto su propia ipseidad (Ringleben, 1995, p. 51). 
Por ello bien puede decirse que el espíritu, que es aquello que en última instancia cada existente es, no es ni una idea, ni un concepto, ni una sustancia, sino, fundamentalmente, una acción que se manifiesta en los modos de la síntesis anímico-corpórea.

Pero el espíritu no sólo se manifiesta a través de la síntesis de cuerpo y alma. En tanto espíritu, el hombre es también y concomitantemente «una síntesis de infinitud y finitud, de lo temporal y lo eterno, de libertad y necesidad; en una palabra: es síntesis. Y una síntesis es la relación entre dos términos» (Kierkegaard, 2008, p. 33). Uno podría preguntarse, entonces, ¿qué significa que el hombre sea síntesis de infinitud y finitud, de temporalidad y eternidad, de libertad y necesidad?

Pues bien, en primer término, la infinitud del existente remite a la originaria indeterminación de su ser como un originario poder-ser. Esto supone que, en un orden lógico, antes de elegir un modo de ser u otro, el hombre puede ser de múltiples maneras. En este sentido, lo infinito refiere a lo indeterminado de la posibilidad desde el plano del pensamiento. Por otro lado, la finitud remite al orden fáctico-existencial de la posibilidad que implica su carácter de determinada. Es decir, lo finito hace referencia a una u otra posibilidad fáctica existencial por la que el individuo se decide. En otros términos, si bien las posibilidades del existente son múltiples en un orden lógico, en el plano fáctico existencial las posibilidades son acotadas. En el instante en el que el existente se decide por una posibilidad fáctica existencial u otra y, así, determina la infinitud lógica de la posibilidad, deviene espíritu. Continuando con el ejemplo del músico, éste sólo deviene espíritu en tanto se elige a sí mismo como músico en su relación con el mundo de la música a través de un cierto estilo y no otro de hacer música.

Al mismo tiempo, Kierkegaard concibe al hombre como síntesis de eternidad y temporalidad. Pero, ¿qué es lo eterno? Para Haufniensis, «el espíritu es lo eterno, y, por eso, sólo se da cuando el espíritu pone a la vez la primera síntesis como la segunda síntesis de lo temporal y de lo eterno» (Kierkegaard, 2016a, p. 203). La «primera síntesis»-síntesis de cuerpo y alma- es puesta por el espíritu y es necesaria para el darse de lo eterno. Esta primera síntesis de cuerpo y alma configura la dimensión temporal de la síntesis. Ahora bien, la «segunda síntesis tiene solamente dos momentos: lo temporal y lo eterno» (Kierkegaard, 2016a, p. 198). Mientras que lo temporal configura la temporalización de lo sintetizado, lo eterno es el espíritu que ejecuta esta síntesis de un cierto modo. Así, la segunda síntesis es la relación sintética que mantiene el espíritu con la síntesis de cuerpo y alma que él obra. El espíritu es síntesis de eternidad y temporalidad en la medida en la que, relacionándose a sí con la primera síntesis, pone la segunda síntesis. Dicho de otro modo, cuando el espíritu se relaciona con la síntesis de cuerpo y alma, entonces lo eterno -el espíritu en tanto libertad que no puede surgir de la determinación causal imperante en el orden del tiempo- se sintetiza con lo temporal -la relación entre el alma y el cuerpopara determinar en cada caso la existencia del hombre singular.

En tercer lugar, el existente es síntesis de libertad y necesidad. Víctor Eremita se pregunta por el ser del sí mismo, frente a lo que responde: «Si quisiera mencionar su primer momento, su primera expresión, respondería: es lo más abstracto de todo, que es además, sin embargo, lo más concreto de todo -es la libertad» (Kierkegaard, 2007, p. 195). La libertad es una de las condiciones ontológicas fundamentales del ser sí mismo. El existente, en tanto ser posible, es libre. La libertad del espíritu se funda en su ser como posibilidad. Ser sí mismo libre es ser un ser posible. El existente puede decidir y determinar quién ha de llegar a ser en su elección de sí como el ser posible que él es. Este llegar a ser es esencialmente libre, en tanto que «todo llegar a ser acaece por libertad, no por necesidad; nada que llegue a ser llega a ser por un fundamento, sino siempre por una causa» (Kierkegaard, 2016b, p. 87). Pero esta causa no está determinada, sino que es la libertad 
como causalidad: «Toda causa culmina en una causa libremente actuante» (Kierkegaard, 2016b, p. 87). En este sentido, el existente, que no es una esencia fija, sino que constantemente está llegando a ser quién ha de ser, es libertad y posibilidad. El existente es libre en tanto decide llegar a ser el sí mismo particular que él es. En efecto, para Climacus «la libertad consiste en ser sí mismo» (Kierkegaard, 2016b, p. 32). Ahora bien, esta libertad no es absoluta, sino más bien relativa, ya que es una condición que le ha sido dada al espíritu. La libertad no tiene su origen en el espíritu, sino que es padecida por él. Esto quiere decir que el espíritu es libre y no puede no serlo, en tanto no puede renunciar a la condición de libertad que le ha sido dada. En este sentido, la posibilidad de la libertad no consiste en elegir entre una cosa u otra, «la posibilidad de la libertad no consiste en poder elegir entre el bien y el mal» (Kierkegaard, 2016b, p. 166). Haufniensis ubica la libertad en un plano más originario: aquel en el que la posibilidad consiste en una posibilidad de poder. En este plano originario, la libertad se sintetiza con la necesidad, porque el hombre no puede no poder, no puede no ser sus posibilidades. Puede no ser ésta u otra posibilidad pero no puede negar que su ser es ser-posible. El espíritu es el existente que decide libremente elegirse a sí mismo en el instante en el que libertad y necesidad se sintetizan.

\subsection{El instante como temporalidad de la existencia auténtica}

La síntesis en sus cuatro dimensiones - cuerpo y alma, finitud e infinitud, temporalidad y eternidad, libertad y necesidad - es puesta en el instante en el que el existente asume su condición de espíritu y se elige a sí mismo como tal en la existencia auténtica. En el instante en el que el existente se relaciona a la síntesis que él es y elige libremente ser sí mismo, deviene espíritu. En efecto, Kierkegaard sostiene que «en el momento en que el espíritu se pone a sí mismo, pone la síntesis» (Kierkegaard, 2016a, p. 165). El momento en el que el espíritu «se pone a sí mismo» es el instante: «tan pronto como el espíritu está puesto, el instante está ahí» (Kierkegaard, 2016b, p. 201). En el instante acontece «la plenitud de los tiempos», toda vez que en él se conjugan los éxtasis de la temporalidad: pasado, presente y futuro. El futuro, en tanto advenir, se sintetiza con mi propio presente asumido como proyección de este presente; y con mi pasado, que se recupera como condición de posibilidad de este presente asumido y, de ese modo, recibe retrospectivamente un sentido integral. En síntesis, el instante -fenómeno cuyo análisis detenido escapa a los objetivos de este artículo- funge como aquella concentración de los horizontes temporales por obra de la cual pasado y futuro quedan integrados al presente que irradia hacia ellos sentido. Él es la temporalidad propia de la existencia auténtica.

Ahora bien, cabe preguntarnos: ¿cuándo acaece el instante? El instante no puede producirlo el existente, sino sólo recibirlo y asumirlo. Él se da cuando, entre las posibilidades de las que dispongo en la situación concreta en la que me encuentro, se me ofrecen y asumo -en el sentido de que me comprometo con ellas-ciertas posibilidades que me plenifican, que me hacen ser más auténtico, en tanto que, en virtud de mi relación con ellas, me decido a ser el sí mismo particular que soy. El existente que deviene espíritu en el instante [øye-blikk] es, para Kierkegaard, entonces, aquel que echa una mirada [blikk] a la situación fáctica en que se encuentra y, en ese momento, se elige a sí mismo, asumiendo ciertas posibilidades que le son dadas. Y lo hace de modo tal que involucra todo su ser en sus elecciones. Tal es el individuo de la existencia auténtica: aquel que compromete su ser de manera total e íntegra con aquello que elige de entre lo que le es dado, y, de ese modo, se asume a sí mismo como espíritu. 


\section{Ser sí mismo como Dasein}

\subsection{La pregunta por el ser}

Es sabido que en el transcurso de los años 1914-1927², Heidegger dedicó gratos esfuerzos a la lectura y análisis de las obras kierkegaardianas, en especial a $O$ lo uno o lo otro, Migajas filosóficas y El concepto de la angustia. En efecto, en 1923, en el último curso dictado en Friburgo antes de partir a Marburgo, Heidegger reconoce explícitamente: «impulsos me los dio Kierkegaard» (Heidegger, 2000, p. 22). Es mi intención aquí dar a conocer la comprensión del ser sí mismo como Dasein, teniendo en cuenta la recepción heideggeriana de la concepción kierkegaardiana de existencia operante en algunos de los conceptos que nuestro pensador retoma de quien él mismo reconoce como impulsor suyo en este sentido.

En 1927, Heidegger señala la necesidad de volver a hacer la pregunta que interroga por el sentido del ser y procura dilucidar aquello de que se pregunta [das Gefragte] así como aquello a que se pregunta [des Befragte] la pregunta por el ser. Aquello "de que" se pregunta «es el ser, aquello que determina a los entes en cuanto entes, aquello "sobre lo cual" los entes, como quiera que se los dilucide, son en cada caso ya comprendidos» (Heidegger, 2010, p. 15). Mientras que aquello "a que" se pregunta «son los entes mismos. A estos se los interroga, cabe decir, acerca de su ser» (Heidegger, 2010, p. 16). El "a que" se pregunta -que es el que aquí nos interesa- remite a aquel ente que comprende el ser de los entes, esto es, al existente humano, aquel ente cuya condición fundamental de ser es ser ontológico, es decir, comprender los entes en su ser. Este modo específico de comprender el ser del ente es revelado en el modo de ser particular de cada existente, es decir, en el modo en que cada existente se relaciona con los demás entes. En este sentido, la pregunta por el ser es una pregunta existencial, es la pregunta por el existir, en tanto aquello "a que" se pregunta la pregunta es el ser sí mismo, el existente.

\subsection{El "ahí" del ser}

El ente entre los entes capaz de preguntar por el sentido del ser es el Dasein (ser-ahí): «Este ente que somos en cada caso nosotros mismos y que tiene entre otros rasgos la "posibilidad de ser" del preguntar, lo designamos con el término "ser ahí"» (Heidegger, 2010, p.17). El Dasein es el único ente cuyo modo de ser consiste en comprender el ser de los entes. Heidegger explicita la exégesis ontológica originaria del ser de este ente en su analítica existenciaria del ser del "ser ahí" de Ser y tiempo, dirigiendo la mirada a la estructura fundamental de este ente: la existencia.

El Dasein o "ser ahí" es el "ahí" del ser, es decir, el "lugar" en el que el ser se manifiesta. La estrecha correlación que existe entre el ser y el "ahí" es radical: no es posible que haya ser sin "ahí”, ni "ahí” sin ser. En efecto, el término alemán Da-sein señala el "estado-de-abierto" de este ente: la apertura del "sí mismo" a su ser más originario, es decir, la comprensión originaria del ser que le corresponde al existente en tanto le es propio el "ser ahí" como modo de ser fundamental. En este sentido, el ser se le revela al "ser ahí" porque su modo de ser fundamental consiste en "preguntarse por", es decir, en "estar-abierto-a" la manifestación del ser del ente.

Cfr. GA 1, p. 56. 
Es ya sabido que el Dasein no es el hombre concreto y particular, sino más bien el fundamento de todo hombre en tanto tal: aquello que le da u otorga al individuo su propia esencia, a saber, la existencia. En efecto, para Heidegger: «la "esencia" del "ser ahi' está en su existencia» (Heidegger, 2010, p. 54). A través de ella realiza su comprensión del ser; y, de este modo, abre para el ser un “ahí". Que la existencia sea la esencia del "ser ahí" significa que el ser del existente - tal como ocurría con Kierkegaardno es un ser sustancial, cuya esencia le es dada de antemano, sino que señala, por el contrario, que su ser es su tarea. Existir es una tarea: el Dasein debe hacerse a sí mismo en cada caso. Su ser está sujeto a un constante tener que hacerse.

Esto se vuelve más claro en la caracterización que Heidegger hace del sí mismo cuando señala que a éste le va su ser: «el ser que le va a este ente en su ser es, en cada caso, mío [je meinig]» (SZ, p. 42/Heidegger, 2010, p. 54). Que al Dasein "le va" su ser significa, por un lado, que el existir implica la comprensión de su ser, y por otro, que su ser es su tarea. No sucede de igual modo con los demás entes, a los cuales su ser no sólo les resulta indiferente, sino que ya les está dado por anticipado, por lo que no pueden sino realizar esa esencia que les fue conferida de antemano.

Pero, ¿cuál es la tarea en la que consiste el existir del Dasein? El existir -el tener que hacerse-consiste en hacer ser por mí mismo mi modo de ser en función del modo en que comprendo mi ser y el ser de los entes con los que me relaciono. Es decir, la manera en la que el existente comprende su ser y el de los demás entes determina su modo de ser.

Teniendo en cuenta esta última afirmación -según la cual para Heidegger el modo de ser del Dasein es determinado por la comprensión de su propio ser y del ser de los demás entes- resulta atinado señalar lo postulado por Gerard Thonhauser en Ein rätselhaftes Zeichen. Zum Verhältnis von Martin Heidegger und Søren Kierkegaard ${ }^{3}$.

Según lo afirmado allí por Thonhauser, existiría cierta relación de semejanza entre la determinación del sí mismo como espíritu y la del sí mismo como Dasein. Sin embargo, Heidegger se alejaría de la concepción kierkegaardiana del sí mismo en su determinación de la existencia como comprensión del ser, aspecto que su predecesor no habría considerado: «Especialmente con su determinación del Dasein como una relación con el ser, Heidegger pudo basarse en Anti-Climacus. Es una reminiscencia de la formulación de La enfermedad mortal [...]. En vista de esta conexión, la valoración de Heidegger expresada en Ser y tiempo de que Kierkegaard sólo se preocupa por las determinaciones existenciales, pero que los problemas existenciales le son ajenos, parece inapropiada. Las determinaciones estructurales del sí mismo que se pueden encontrar en La enfermedad mortal son un aspecto con el que Heidegger pudo relacionarse. Sin embargo, si se tiene en cuenta esta importante corrección, la valoración de Heidegger me parece justificada: con una nota manuscrita en su ejemplar de Ser $y$ tiempo, Heidegger aclara de qué se trata esta afirmación. Él precisa qué se entiende por "problema existencial": "[...] lo ontológico fundamental, es decir, la cuestión del ser como tal en general". En este punto entra en juego otra determinación: Heidegger determina la existencia no sólo como una relación al ser, sino también como una comprensión del ser. Este segundo elemento estructural agrega un elemento a la determinación de la existencia que no está contenido en la determinación del yo de Anti-Climacus. Heidegger llama la atención sobre esto en una interpretación posterior: "El concepto 'existencial' [existenzielle] de existencia (de Kierkegaard y Jaspers) supone el ser óntico del hombre [das selbstseiende Selbst des Menschen], en la medida en que está interesado en sí mismo como este ente. El concepto 'existenciario' [existenziale] de existencia supone el ser sí mismo del hombre, en la medida en la que él no se relaciona con el sí mismo óntico, sino con el ser y con la relación con el ser". Con esta determinación -la comprensión del ser- el Dasein recibe una dimensión ontológica que apunta a una cuestión que no se plantea así en La enfermedad mortal: la cuestión ontológica de la determinación de los entes en general. Heidegger llama la atención sobre el hecho de que el Dasein no sólo comprende su propio ser (esto es algo que también es importante para la autodeterminación en La enfermedad mortal; en este sentido, las determinaciones allí desarrolladas también se extienden al problema existencial), sino que el Dasein se distingue por poder preguntar sobre el ser de los entes» (Thonhauser, 2016, pp. 278-279). 
En el acápite 14, Thonhauser busca señalar la relación de similitud y diferencia entre la determinación de la constitución ontológica del Dasein en la introducción de Ser y tiempo y la determinación del sí mismo en la primera sección de La enfermedad mortal. Allí sostiene que Heidegger retomaría de Anti-Climacus la determinación del sí mismo como relación con el ser. Sin embargo, Heidegger señalaría un aspecto que Kierkegaard hubiera dejado de lado: la cuestión ontológica de la determinación de los entes en general. A diferencia del espíritu, el Dasein no sólo estaría determinado ontológicamente por el modo en que se comprende a sí mismo, sino también por el modo en que comprende el ser de los entes. A mi modo de ver, Kierkegaard no le otorga un grado de primordialidad a la determinación de los entes en general, porque el sí mismo es fundamentalmente relación consigo mismo, a diferencia del Dasein que es prioritariamente relación al ser. Sin embargo, no deja de considerarlos, ya que el sí mismo es relación que se relaciona consigo misma a partir de su relación con los demás entes.

Seguidamente, Thonhauser menciona el motivo presumible por el cual Heidegger no habría incorporado en su determinación del ser del Dasein el concepto kierkegaardiano de síntesis ${ }^{4}$. En este punto, en concordancia con lo postulado por Paul Kuder ${ }^{5}$, me permito disentir con Thonhauser, ya que estimo que, si bien es cierto que Heidegger no incluye en su definición del sí mismo el concepto kierkegaardiano de síntesis, no lo haría por considerarla una reformulación del dualismo cartesiano de la sustancia como supone Thonhauser-, ya que Kierkegaard nunca plantea la síntesis como síntesis entre una res cogitans y una res extensa, sino entre distintas facultades o funciones del existir, tal como lo he mencionado en el apartado 1.3, en el que me refiero a la determinación kierkegaardiana del hombre como síntesis.

\subsection{Facticidad y posibilidad}

Tal como ha sido dicho en el apartado anterior, la tarea en que consiste el existir radica en hacer ser mi modo de ser de acuerdo al modo en que comprendo mi ser y el de los entes del mundo. Desde el punto de vista ontológico constitutivo, "facticidad" mienta la estructura del Dasein por la cual éste ya siempre existe y tiene que hacer ser su ser como tarea. Ello implica, consecuentemente, que el Dasein ya siempre también tiene que proyectarse a un poder-ser. En efecto, el ser del Dasein en tanto existente que comprende su ser es "poder-ser". Por lo tanto, que al Dasein "le va" su ser como tarea suya se concreta por medio de la elección de un determinado ser-posible, en función

4 «Una determinación de La enfermedad mortal que Heidegger no retoma es la del hombre como síntesis [...] Heidegger no comenta explícitamente este aspecto: sin embargo, es obvio que para Heidegger esta definición debía aparecer como una reformulación de un dualismo cartesiano de sustancias. En general, el proyecto de Ser y tiempo puede entenderse como un intento de superar la ontología cartesiana. En este sentido, esta definición del hombre como síntesis de polos limitantes y delimitantes - ecos de la clásica distinción entre res cogitans y res extensa- fue interpretada por Heidegger, presumiblemente, como una influencia de la tradición ligada a Descartes, que no vale la pena continuar, por lo que simplemente él ignoró este aspecto» (Thonhauser, 2016, pp. 279-280).

5 En Kierkegaards Heidegger, Paul Kuder sostiene que ubicar a Kierkegaard dentro del paradigma cartesiano implicaría una interpretación errónea de sus textos: «A primera vista, las reflexiones de Kierkegaard se asemejan al paradigma cartesiano de la filosofía de la conciencia, que distingue esquemáticamente entre un sujeto cognoscente y un mundo exterior que se opone a este sujeto. Una vez más, se malinterpreta el estado de las consideraciones de Kierkegaard si se quiere dejarlo en ese punto de vista» (Kuder, 2015, p. 106). 
del cual se relaciona consigo mismo y con el mundo. Siendo, el sí mismo se relaciona a su ser más propio como posibilidad.

Pero esas posibilidades hacia las que se proyecta son limitadas. Por la condición de su ser como ser-posible-finito, el Dasein se proyecta sobre las posibilidades que en una cierta situación le son posibles. Por ello, la significación ontológica de la facticidad, a saber, el hecho de que al Dasein le ha sido dado su ser como existencia y de que tiene que ser -tiene que cumplir su existencia como tarea- se concreta ónticamente como la elección y consecuente asunción de las posibilidades fácticas finitas que cada situación le ofrece al Dasein. En tal sentido puede leerse la siguiente declaración de Heidegger: "Facticidad es el nombre que le damos al carácter de ser de "nuestro" existir "propio"» (Heidegger, 2000, p. 25).

Ahora bien, que el existente es capaz de elegir el modo en que él es, es decir, el modo particular en el que decide relacionarse con sus posibilidades, no significa que él sea capaz de establecer su propio ser. Es cierto que el existente determina el modo en que existe a partir de su relación con las posibilidades fácticamente posibles. Sin embargo, él no elige su ser como existencia. En la ontología heideggeriana, el ser sí mismo pertenece al ser (genitivo subjetivo) en tanto éste lo entrega a la existencia y, de ese modo, lo determina a ser el "ahí" en el cual el propio ser puede venir a la luz. Es por eso que Heidegger concibe al Dasein como el punto de entrecruzamiento del ser y del hombre.

Ésta es la facticidad fundamental, a la que me referí anteriormente al hablar de facticidad como estructura ontológica del existente. Esta facticidad ontológica delata cierto grado de pasividad última en la constitución del ser del Dasein. A mi modo de ver, en esa pasividad última se reconoce la pasividad que determina también la constitución fundamental del ser sí mismo como espíritu en Kierkegaard. Por otro lado, la concreción óntica de la facticidad ontológica como asunción de las posibilidades que la situación ofrece refleja, también -aunque con ciertas diferencias a las que habremos de referirnos más adelante- la concepción kierkegaardiana del sí mimo auténtico, esto es, de aquel que se asume plenamente como espíritu, en tanto y en cuanto éste es el que se decide por las posibilidades fácticas y finitas que se le ofrecen en el instante. Cabría plantearse también aquí si la aceptación de la facticidad de la situación en la decisión del existente auténtico no implicaría, además, una síntesis entre los condicionamientos fácticos que la realidad física impone y la posibilidad de ser proyectada por el Dasein.

\subsection{Ser sí mismo auténtico e inauténtico}

Por ser el Dasein esencialmente en cada caso su posibilidad, «puede este ente en su ser "elegirse" a sí mismo, ganarse, y también perderse, o no ganarse nunca, o sólo "parece ser" que se gana» (Heidegger, 2010, p. 54). Tal como sostiene Kuder, «en la concepción heideggeriana, existencia y ser en cada caso suyo, deben entenderse como condiciones de posibilidad de existencia auténtica e inauténtica» (Kuder, 2015, p. 140).

Para el Heidegger de Ser y tiempo, la existencia oscila entre dos grandes modos de ser posibles: la autenticidad [Eigentlichkeit] ${ }^{6}$ y la inautenticidad [Uneigentlichkeit $]^{7}$. Ambos modos de ser «tienen su fundamento en que todo "ser ahí" se caracteriza por el

O "propiedad", según la traducción de Gaos.

O “impropiedad”, según la traducción de Gaos. 
“ser, en cada caso, mío"» (Heidegger, 2010, p. 55). Esto significa que, siendo el Dasein un ser-posible cuyo existir consiste en tener que hacerse a cada momento, debe elegir entre estos dos modos de ser posibles. El sí mismo que se decide por una existencia auténtica, es aquel que se elige a sí mismo, ganándose a sí; en cambio, el sí mismo que elige existir de manera inauténtica, es aquel que, no eligiéndose a sí mismo, se pierde en el impersonal. Lo cierto es que ambos modos de ser son modos en que el ser [sein] se manifiesta en el "ahí" $[d a]$, de manera auténtica o de manera inauténtica, respectivamente.

Como es sabido, Heidegger llama "uno" [das Man] al sí mismo que se decide por la existencia inauténtica. El "uno" «es un existenciario inherente a la constitución positiva del "ser ahí"» (SZ, p. 128/Heidegger, 2010, p. 146). Éste, que no es "nadie" y que son todos a la vez, establece el modo de ser de la existencia inauténtica, de la cotidianidad de una existencia caída, en la que el individuo se comprende como un ente "ante-losojos": “"Uno" es en el modo del "estado de ser no en sí mismo" y la "impropiedad”» (SZ, p. 128/Heidegger, 2010, p. 145). El uno es el existente que se relaciona con sus posibilidades de un modo impropio, en tanto, eligiéndolas, no se elige a sí mismo. Por el contrario, se oculta a sí mismo su propio ser y se pierde en lo impersonal de las masas, haciendo lo que se hace, hablando como se habla y de lo que se habla, pensando tal cual se piensa. El uno es aquel sí mismo que, sabiéndose único e irrepetible, decide no ser quién es y se conforma con pertenecer a un sistema masificador que permanece encerrado en los límites de lo similar.

Por su parte, el sí mismo que se decide por la existencia propia «es una modificación existencial del "uno", en cuanto éste es un esencial existenciario» (SZ, p. 130/ Heidegger, 2010, p. 147). El sí mismo auténtico está abierto a su ser más propio como comprender y como ser-posible. El "ser ahí" propio es aquel que asume y empuña su propia condición ontológica que es la existencia. La autenticidad es el modo propio del existir, es aquel modo de ser elegido por el Dasein que acepta y asume su propia condición ontológica, la propia existencia, aquello a lo que está llamado a ser. Hacerlo le significa aceptar su condición finita de ser-posible.

Heidegger retomaría de Kierkegaard su concepción de la autenticidad en cuanto la existencia auténtica se da, para Heidegger, por la concreción óntica de la facticidad ontológica como asunción de las posibilidades que la situación ofrece. De igual modo sucede para Kierkegaard: el sí mismo auténtico -sí mismo como espíritu- es aquel que se decide por las posibilidades fácticas y finitas ofrecidas en el instante ${ }^{8}$. En Los lirios del campo ${ }^{9}$, Kierkegaard afirma que el hombre debe contentarse con ser hombre. Podríamos deducir de allí que para Kierkegaard existe auténticamente quien se contenta con ser hombre. Contentarse con ser hombre implica, para Kierkegaard -y también para Heidegger-, asumir la propia facticidad. Por ello afirma Thonhauser: «Su tarea [la

8 Si bien es cierto que Heidegger intentaría retomar cierto aspecto de la comprensión kierkegaardiana de la elección de sí mismo en la existencia auténtica, no resulta menos cierto que para algunos se trata de un intento insuficiente, superfluo y hasta insignificante. Sin embargo, no deja de ser destacable el grado de fundamentalidad que Heidegger le concede a la comprensión kierkegaardiana acerca de la elección de sí mismo en su propia comprensión de la existencia auténtica del Dasein en la que éste asume su ser como poder-ser. Así lo afirma Kuder en Kierkegaards Heidegger: «se podría argumentar de manera extremadamente polémica que Ser y tiempo, más precisamente en su culminación del análisis de la autenticidad, representa este "intento superfluo" [...]. Es cierto que los pasajes sobre la elección de sí mismo en Ser y tiempo ocupan un espacio insignificante. Sin embargo, los coloca en un lugar elemental: se trata de "atestiguación, por el "ser ahí" mismo, de un "poder ser" propio» (Kuder, 2015, pp. 150-151).

9 Cfr. Kierkegaard, 1963, pp. 37-66. 
del hombre] consiste en lo siguiente, primero que él tiene que asumir su facticidad, independientemente de qué forma pudiera cobrar en cada particular esta facticidad, y segundo que él tiene que proyectarse hacia su futuro de cara a ella» (Thonhauser, 2011, p. 183).

Esto no hace más que dejar en evidencia la directa recepción heideggeriana de la comprensión kierkegaardiana acerca de la autenticidad y la elección de sí mismo ${ }^{10}$. Siguiendo las palabras de Kuder, se trataría de una "adaptación" de los términos kierkegaardianos desplegados en las cartas de B de $O$ lo uno o lo otro a los términos heideggerianos de Ser y tiempo:

Las declaraciones de Heidegger sobre la elección de sí mismo muestran un carácter genuinamente activista-existencialista. Debido a la sorprendente similitud con el concepto de elección de B de $O$ lo uno o lo otro, se puede suponer que Heidegger simplemente lo adaptó. De modo que transfiere pensamientos centrales de $O$ lo uno o lo otro a la concepción de la autenticidad de Ser y tiempo (Kuder, 2015, p. 152).

\subsection{Ser sí mismo auténtico: el "precursar"}

Como hemos visto, el ser del Dasein es un ser-posible. El "ser ahí" es aquel que se halla siempre ya proyectado hacia el conjunto de posibilidades que le son fácticamente posibles. Ahora bien, el Dasein que se decide por una existencia auténtica es aquel que, asumiendo su propia facticidad y eligiéndose a sí mismo como ser-posible, se proyecta sobre su posibilidad más propia: la de "ser relativamente a su muerte".

La totalidad de las posibilidades desembocan en la posibilidad de la muerte. Ella es la más propia de las posibilidades por los caracteres que la determinan: «desde la perspectiva de Ser y tiempo la muerte es la posibilidad más propia de cada Dasein, porque ella es, por antonomasia, la posibilidad irreferente, irrebasable, cierta, pero, por lo pronto, indeterminada del existir» (Garrido-Maturano, 2018, p. 57). Por ser irreferente, la muerte me singulariza: ella es sólo mía y de nadie más; por ser irrebasable, el Dasein no puede ir más allá de ella; por ser cierta, la muerte es la posibilidad más segura de la existencia; finalmente, por ser indeterminada, la muerte es siempre ya posible. Por todo esto, la posibilidad de la muerte es la posibilidad más propia del existente.

Si todas las posibilidades del sí mismo desembocan en el horizonte último de la posibilidad de la muerte, entonces ésta es la posibilidad más peculiar: en el modo de relacionarse con ella, el Dasein pone en juego la totalidad de sus posibilidades, y

10 Kuder señala, a nuestro entender, con razón, que Heidegger criticaría la ausencia de una filosofía existencial en Kierkegaard, pero, sin embargo, no haría más que retomar los puntos clave de la comprensión kierkegaardiana de la existencia: «Heidegger critica a Kierkegaard por una conciencia existencial insuficiente, pero adopta argumentos centrales de B en su análisis existencial» (Kuder, 2015, p. 152). Y más adelante agrega: «Señalamos que Heidegger ya en la página 42 de Ser y tiempo define el momento de la elección como esencial para su concepción del Dasein y de la existencia. Si reunimos los pasajes citados de la página 42 y la página 268 de Ser y tiempo [...], se muestra que el análisis existencial de Heidegger en Ser y tiempo oculta una capa existencialista en su forma más pura, cuyo lugar sistemático radica en la cuestión de la transición de la inautenticidad a la autenticidad. Inherentemente hay una base existencialista. Un pensamiento que determina al Dasein como elección autónoma; un pensamiento que reflexiona sobre el Dasein que se apropia de sí mismo en el sentido de un "acto interior", elige y "gana" - un pensamiento que implica así una concepción existencialista y también una concepción sugestivamente teleológica de la existencia, desplegada hacia la autenticidad» (Kuder, 2015, pp. 152-153). 
por tanto, se juega allí la totalidad de su ser como ser-posible. El sí mismo auténtico es aquel que elige sus posibilidades en función de la totalidad de su existencia y orientado hacia su muerte, es aquel que asume la facticidad en una situación que se abre y se articula desde el "precursar" [Vorlaufen] la propia muerte. En este sentido, lo propio de la existencia auténtica consiste en asumir la situación fáctica desde el "precursar" la muerte.

"Precursar" la propia muerte es asumir nuestro ser como ser finito y como ser-posible desde el horizonte de la posibilidad en la que desembocan la totalidad de las posibilidades. Es un sí mismo auténtico aquel que proyecta a cada instante el conjunto de sus propias posibilidades sobre el horizonte de la posibilidad de la muerte. Por lo tanto, existir de manera auténtica, por el "precursar" la propia muerte, quiere decir «hacer posible la posibilidad de la muerte» (Garrido-Maturano, 2018, p. 58). Ser sí mismo auténtico no es más que elegir el modo de ir muriendo.

Aquí es donde Heidegger se distingue de Kierkegaard: en su concepción acerca del modo de consumación de la facticidad. Mientras que para Heidegger la consumación de la facticidad es la muerte y mi relación con ella -relación que determina la autenticidad del resto de mis posibilidades-, para Kierkegaard no es la certeza de la propia muerte lo que le impide ni lo que le posibilita al sí mismo la tarea de llegar a ser sí mismo, sino su propia desesperación o la superación de esa enfermedad mortal. En tal sentido, escribe Thonhauser:

Antes bien es el hombre mismo que de cara a esta certeza [la de la muerte] desespera y por obra de esta desesperación se impide a sí mismo llegar a ser lo que él hubiera podido ser. Él se deja desviar y aturdir por la certeza del ocaso, de modo que él no deviene la posibilidad, que le ha sido dado ser, aun cuando a él le fuese adjudicada la más breve existencia (Thonhauser, 2011, p. 185).

\subsection{La angustia originaria}

La asunción de la facticidad desde el "precursar" la muerte es inescindible de la angustia. El existente auténtico que "precursa" su propia muerte, asume -y no esquiva- su propia angustia. Así como el existente kierkegaardiano deviene espíritu a partir de la asunción desde la angustia de la condición que le fue dada, también el sí mismo auténtico heideggeriano es aquel que ha pasado por la angustia y desde ella ha asumido su condición pasiva de ser-posible. La angustia ante la posibilidad de la propia muerte es la angustia originaria en tanto ella constituye la posibilidad en la que desembocan todas las demás.

Al igual que Kierkegaard, Heidegger concibe la angustia como el temple ontológico que constituye el ser de todo hombre en tanto tal. La angustia originaria del Dasein-así como la del espíritu kierkegaardiano- puede ser caracterizada como angustia ante su ser como ser-posible o como angustia ante la indeterminación de la posibilidad. En el famoso parágrafo 40 de Ser y tiempo, Heidegger retoma de Kierkegaard la noción de angustia y su respectiva diferenciación respecto del temor. Nuestro autor sostiene allí que la angustia se diferencia del temor en aquello "ante qué" se angustia la angustia. Mientras que "el "ante qué" del temor es en cada caso un ente intramundano, nocivo, que se acerca en la cercanía desde determinado paraje [...] el "ante qué" de la angustia es el "ser en el mundo" en cuanto tal» (Heidegger, 2010, pp. 205-206). Es decir, mientras que el existente teme de frente a un ente intramundano determinado que lo concierne en un cierto modo de ser fáctico, se angustia esencialmente ante el propio 
ser como ser-en-el-mundo, esto es, como ser-posible que, en sí mismo, no es nada, en tanto está todavía indeterminado. En efecto, «el "ante qué" de la angustia es absolutamente indeterminado» (Heidegger, 2010, p. 206). Este "ante qué" de la angustia es el mismo por el cual el ser sí mismo como espíritu se angustia. En efecto, también para Haufniensis el espíritu se angustia ante la posibilidad como «una nada, la angustiosa posibilidad de poder» (Kierkegaard, 2016a, p.162). Al Dasein heideggeriano, así como al espíritu kierkegaardiano, no lo angustia un ente particular, sino más bien la indeterminación de la posibilidad en la que consiste su existir: lo angustia su ser como pura posibilidad, su existencia como tarea, como un "tener que ser".

La angustia ante la muerte consuma y se funda en la angustia ante el propio ser como ser-en-el-mundo. Esta angustia es propia de todo existente en tanto tal. El Dasein se angustia ante su ser como ser-posible y ante su ser como ser-en-el-mundo: «aquello ante que se angustia la angustia es el mismo "ser en el mundo"» (Heidegger, 2010, p. 207). El mundo se configura como el "ante qué" y también como el "por qué" de la angustia del sí mismo. "Aquello por qué se angustia la angustia no es una determinada forma de ser y posibilidad del "ser ahí" [...] aquello por que se angustia la angustia es el "ser en el mundo" mismo» (Heidegger, 2010, p. 207). La angustia abre al ser ahí a su ser como ser-en-el-mundo, pero no como un ente entre otros entes, sino como el ser cuya existencia consiste en hacer ser su ser en función de posibilidades, pero que en el plano originario permanece ya siempre indeterminado. Por lo tanto, en un sentido originario, lo que angustia al existente es su propio ser como ser-en-el-mundo, como ser-posible que, en sí mismo, no es más que la originaria indeterminación de la posibilidad que él mismo es.

En el estado de angustia originario del existente, los entes intramundanos pierden significancia. El conjunto de los entes "a la mano" y "ante los ojos" pertenecientes al mundo se hunden en la insignificatividad y en la irrelevancia. No le significan absolutamente nada al Dasein. El mundo ya no le "ofrece" nada. El "ante qué" frente al cual se angustia, es la nada de la insignificatividad. Para Heidegger, «lo que caracteriza el "ante qué" de la angustia es que lo amenazador no es en ninguna parte» (Heidegger, 2010, p. 206). Que lo amenazador no sea en ninguna parte no refiere a la existencia de una nada fáctica, sino a ese mundo que ya no tiene sentido para el sí mismo. En otras palabras, lo que angustia a la angustia «es ya "ahí" -y sin embargo, en ninguna parte; es tan cerca, que "angustia" y corta la respiración- y sin embargo, en ninguna parte» (Heidegger, 2010, p. 206).

Esa angustia originaria en la que el mundo se ve hundido bajo el manto de la insignificancia, me abre a mi ser como ser-posible y como ser-en-el-mundo. De frente a esta apertura, puedo elegir elegirme y conquistar mi ser o no elegirme y perder mi singularidad en el horizonte de lo impersonal.

\subsection{Autenticidad e instante}

Para Heidegger, «la constitución ontológica del Dasein se funda en la temporalidad [Zeitlichkeit]» (Heidegger, 1975, p. 278). El tiempo es la condición de posibilidad última en función de la cual el ser del sí mismo se articula. Siguiendo esta línea, desde una perspectiva ontológico-fundamental, la existencia auténtica es un modo de temporalización del ser. Al igual que para Kierkegaard, para Heidegger este modo de temporalización del ser de la existencia auténtica es el instante. La asunción del Dasein de su condición de ser-posible y ser-finito en la respectiva situación fáctica acaece en el instante. 
En efecto, la idea kierkegaardiana de que la autenticidad se consuma en el instante como presente auténtico, que se configura como la asunción de la facticidad, es retomada por Heidegger. La concepción kierkegaardiana de la existencia auténtica como acaecida en el instante en el que el existente se comprende y se elige a sí mismo como espíritu a partir de las posibilidades que le están fácticamente dadas, ejerce una influencia directa en la comprensión heideggeriana de la existencia auténtica como asunción de la situación fáctica, en tanto existir auténticamente para Heidegger significa empuñar las posibilidades que se abren como fácticamente posibles para el Dasein en cada situación. Heidegger retoma de Kierkegaard la determinación de que tal asunción de las propias posibilidades acontece en el presente auténtico de la resolución. Y él lo denomina también, retomando la noción kierkegaardiana, "instante" [Augen-blick].

Para Heidegger, el tiempo se temporaliza siempre desde el advenir: desde la propia muerte. Es por esto que el instante acaece como el presente en el que el Dasein, adviniendo a su futuro más propio, en el "precursar" su propia muerte desde el retro-venir a sus posibilidades sidas, vuelve su ser hacia la situación en la que está y determina las posibilidades que a él, en esa situación, le son fácticamente posibles. Por lo tanto, el instante es el modo de temporalización del ser en el que el existente se resuelve a ser lo que es: un ser finito. En el instante, el Dasein asume su condición presente, la situación en la que el existente existe y en la que "precursa" su propia muerte. Esto habilita la existencia de un tiempo pasado y un tiempo futuro. De lo contrario, sólo existiría el tiempo lineal como pura sucesión de momentos. En este sentido, la conciencia del presente como mi presente, con-figura la existencia de un pasado y un futuro, relacionados con ese presente. Dicha consciencia sólo es posible en el instante en el que el existente asume su propia finitud.

En otras palabras, el instante es el presente auténtico en el que el existente se decide por sí mismo asumiendo su finitud en el "precursar" de su propia muerte, proyectando el conjunto de sus posibilidades sobre la posibilidad última de la muerte. En efecto, «el instante no es otra cosa que la mirada de la resolución en la que se abre y mantiene abierta la plena situación del obrar» (GA 29/30, p. 224).

\subsection{Aportes finales}

La posibilidad de una puesta en diálogo entre ambos pensadores en torno a la cuestión del sí mismo auténtico a partir de una perspectiva fenomenológico-hermenéutica externa, ha puesto en evidencia algunos rasgos esenciales que acercan -así como otros que alejan- la comprensión heideggeriana de la existencia auténtica del Dasein desplegada en Ser y tiempo a los desarrollos kierkegaardianos relativos al ser sí mismo auténtico desplegados en algunas de sus obras pseudónimas.

Ambos pensadores procuran dilucidar la estructura fundamental del ser sí mismo a partir de elementos similares: la existencia como relación y como posibilidad, la distinción de los dos modos de existencia -auténtica e inauténtica-, y los puntos de partida en la comprensión de los fenómenos del instante y de la angustia.

Sin embargo, también es posible reconocer diferencias entre ellos: por un lado, Heidegger se aleja del abordaje que Kierkegaard hace del sí mismo en tanto su interés no está centrado en el existente singular sino más bien en el ser del sí mismo como comprensión del ser. Por otro lado, si bien ambos reconocen la existencia de dos modos de ser, no coinciden en la determinación de la posibilidad más propia del sí mismo por la cual éste se abre a la existencia auténtica. Finalmente, es pertinente señalar una 
diferencia fundamental respecto del grado de pasividad que ambos reconocen en el sí mismo en el acaecer del instante. Intentaré exponer estos puntos de manera sintética y precisa a continuación.

En primer lugar, la existencia como relación y como posibilidad es un rasgo común en ambas filosofías: el sí mismo como espíritu, al igual que el Dasein, es un ser-posible cuya existencia consiste en elegir el modo de ser sí mismo a partir de la relación consigo mismo y con lo otro de sí. En ambos casos, ser sí mismo no es más que existir de un modo u otro desde la relación a las propias posibilidades. El sí mismo como espíritu y el sí mismo como Dasein son seres posibles relacionados a su más peculiar posibilidad de ser.

En segundo lugar, tanto Kierkegaard como Heidegger distinguen dos modos de existencia: la auténtica y la inauténtica. La existencia auténtica supone, para ambos, la concreción óntica de la facticidad ontológica como asunción de las posibilidades que la situación ofrece. En este sentido, ser sí mismo auténtico supone asumir la propia condición como ser-posible-finito y comprenderse a sí como relación a las posibilidades más propias: en el caso de Kierkegaard, aquellas que me realizan históricamente en mi individualidad, aquellas que me constituyen como un "quién" singular con una continuidad histórico-aconteciente"; en el caso de Heidegger, la posibilidad de la propia muerte; en cambio, existir de modo inauténtico supone evadir y escapar del propio sí mismo, esquivando la angustia que conlleva asumir la propia condición.

En tercer lugar, en lo que refiere al fenómeno del instante, podemos señalar que para ambos pensadores la existencia auténtica se temporaliza en el instante. En efecto, Heidegger toma de Kierkegaard la idea de que la asunción de su propia condición y de sus propias posibilidades acontece en el instante. Por último, respecto del fenómeno de la angustia, el mismo Heidegger reconoce explícitamente haber retomado de los análisis kierkegaardianos la distinción entre temor y angustia y el señalamiento de las condiciones del "ante que" de la angustia.

Veamos ahora aquellas comprensiones en las que ambos pensadores se diferencian. En primer lugar, si tenemos en cuenta su interés a la hora de abordar el ser del sí mismo, podemos afirmar con certeza que los análisis de Heidegger se alejan de los planteos de Kierkegaard. Mientras que este último articula los elementos que constituyen al sí mismo en tanto existente singular e individual, Heidegger procura llevar a término una exégesis ontológica del ser del "ser ahí" poniéndola en relación con la cuestión del ser. Su interés está puesto en la formulación de una ontología fundada en la concepción del existente como fuente de comprensión del ser. Heidegger parte de la pregunta por el ser, mientras que Kierkegaard se interesa por la existencia del individuo singular. En razón de la diferencia de intereses existentes entre ambos pensadores, mientras que el sí mismo como espíritu es comprensión de sí, el Dasein es comprensión de sí, pero también del ser y de los entes en general - de modo tal que el modo de ser del sí mismo auténtico es determinado por su relación con el ser y con los entes del mundo-. Kierkegaard no desarrolla este aspecto, en tanto no le concede el mismo grado de primordialidad al ser. Por su parte, y a raíz de su concepción del sí mismo como comprensión de sí y del ser de los entes, Heidegger considera que la existencia no es una categoría exclusiva del existente singular e individual, sino que le corresponde también al existente en un orden colectivo: es decir, como pueblo. Esto sería impensable desde la perspectiva del filósofo danés.

En segundo lugar, la posibilidad auténtica a la que se relaciona el sí mismo que se ha decidido por una existencia auténtica es diferente en ambos casos. Para Kierkegaard, la posibilidad más propia es aquella que concierne a mi propia realización. Se trata, más bien, del conjunto de posibilidades plenificadoras que me configuran como un quién 
dotado de una historia personal, que es constituida a partir de mis propias posibilidades relacionadas de manera continua y articuladas en una situación que se despliega de manera temporal. Ser sí mismo auténtico supone, en este sentido, decidirse por aquella posibilidad que llene de sentido mi existir y que comprometa todo mi ser, que forme parte de mi historia personal. No una posibilidad entre otras, sino aquella que de sentido a mi ser y a todo lo que me rodea. En cambio, para Heidegger, la posibilidad auténtica es la posibilidad última de la muerte. La continuidad histórica del ser sí mismo como Dasein se abre, para Heidegger, desde el "precursar" la propia muerte. El ser sí mismo auténtico es aquel que se relaciona al conjunto de sus posibilidades siendo consciente de su finitud: elige sus posibilidades sabiendo que en algún momento va a morir.

En tercer lugar, Heidegger se diferencia del planteo kierkegaardiano sobre el fenómeno del instante. Es cierto que ambos parten de la comprensión del instante como temporalización de la existencia auténtica. Sin embargo, Kierkegaard reconoce en el ser sí mismo como espíritu que se abre al instante un grado de pasividad mayor. Para el danés, el instante le sobreviene al espíritu en algún momento de su existencia: él viene a su encuentro de manera casi secreta, "a hurtadillas". El instante se le es dado por el modo en que se le ofrece la realidad. El sí mismo como espíritu recibe pasivamente este instante que se le es dado. En cambio, para Heidegger es el Dasein el que abre el instante desde el "precursar" la propia muerte. Para el alemán, el instante es puesto por el "ser ahí" en el momento en el que éste se proyecta sobre sus posibilidades sabiendo que ha de morir. El instante no viene al existente, sino que es puesto por él.

Para Kierkegaard, el instante se abre desde el temple de la fe. Pero no una fe confesional, sino una más fundamental y originaria: la fe en que mi existencia puede tener un sentido y en que ese sentido me es dado. El instante hace que mi existencia tenga sentido para el todo y que todo tenga sentido para mí. El instante es el presente de la armonía plena. En cambio, para Heidegger el instante es abierto por el Dasein desde el temple de la angustia del "precursar" la propia muerte. El presente auténtico ocurre cuando se abre la situación fáctica respectiva desde una actitud del "ser ahí" de asumir su condición de ser-finito. En otras palabras, el instante acaece como la resolución del Dasein que se relaciona con sus posibilidades desde el "precursar" la muerte, desde la conciencia de su finitud. Por lo tanto, mientras que para Kierkegaard es el instante el que produce la resolución del espíritu, para Heidegger es la resolución del Dasein la que produce el instante.

Esta última diferenciación nos permite evidenciar otra más referida a la comprensión de la temporalización. Para Kierkegaard, el tiempo se temporaliza siempre desde el presente, desde el instante. Es el presente el que determina las posibilidades. El sí mismo como espíritu se proyecta hacia sus posibilidades futuras desde su horizonte presente. La mirada está puesta en el presente. En cambio, para Heidegger, el tiempo se temporaliza siempre desde el advenir, desde la propia muerte. Es el futuro el que determina las posibilidades. El Dasein se proyecta hacia sus posibilidades desde el horizonte de la posibilidad de la muerte: el presente auténtico se abre desde la proyección de la muerte. Podríamos decir, entonces, que la mirada está puesta en el futuro.

Para ambos pensadores, el sí mismo, frente a la posibilidad, se angustia. Tanto para Kierkegaard como para Heidegger, la angustia es el temple ontológico que determina la estructura fundamental del ser de todo hombre. Ambos conciben esta angustia originaria como angustia ante mi ser como ser-posible, como angustia ante la indeterminación de la posibilidad. Se trata de la angustia de quien sabe que puede ser y no sabe nada acerca de qué puede ser. Sin embargo, la angustia se concreta de un modo diferente en cada caso.

Para Kierkegaard, el espíritu se angustia ante la posibilidad de no ser hoy el sí mismo particular que se le ofrece ser y ante la posibilidad de no decidirse por una vida integral, 
continua, histórica, en la que pueda desarrollar, en armonía con los otros y con el mundo, las posibilidades fácticas que le son dadas. Dicho de otro modo, el espíritu se angustia ante la posibilidad de no asumirse como el espíritu finito que él es con la ayuda del Poder que lo puso como ese sí mismo que es y que lo deja ser, ofreciéndole en cada situación particular un conjunto de posibilidades de ser, por medio de la apertura de una realidad fáctica en la cual éste puede ser quien es. Pero por sobre todo, el espíritu se angustia ante la posibilidad de la nada: de que la muerte -individual y general-desemboque en el absurdo del sinsentido, consumiendo una vida para nada. En este sentido, la angustia es angustia ante el hecho de que la posibilidad indeterminada-que antes de ser elegida y asumida es nada- nos conduzca a la nada del sinsentido. Sin embargo, para Kierkegaard, no es posible permanecer angustiado indefinidamente, sino que es necesario saltar, ya sea a la desesperación de la falta de espíritu o a la fe en que todo tiene un sentido absoluto que el espíritu no puede producir ni conocer, y que para Kierkegaard se encarna, por antonomasia, en el cristianismo.

En cambio, para Heidegger, el Dasein se angustia ante la posibilidad de la propia muerte, es decir, ante la posibilidad de dejar de ser mañana el sí mismo que hoy ha decidido ser. La angustia es angustia ante la posibilidad de dejar de ser. A diferencia de la propuesta kierkegaardiana, para Heidegger la autenticidad no radica en saltar, sino en permanecer angustiado hasta el final. Esto sucede concretamente en el precursar, en tanto la angustia ante mi ser como ser-posible es angustia ante la posibilidad que contiene todas las demás posibilidades, incluso antes de su determinación: es decir, la posibilidad de la muerte. De este modo, mientras que para Kierkegaard la angustia es angustia ante dejar de ser sin haber sido quien se podía haber sido y morir sin haber sido uno mismo en plenitud, para Heidegger la angustia es tan sólo angustia ante dejar de ser, es decir, ante la propia muerte.

\section{Referencias}

GARRIDO-MATURANO, Ángel E. (2018). "Instante y situación. Problematización de la relación entre instante y situación entorno a Ser y tiempo de Martin Heidegger", en Ágora: Papeles De Filosofía, 37(2), pp. 53-75. Doi: https://doi.org/10.15304/ ag.37.2.4144.

HEIDEGGER, Martin (2000). Ontología. Hermenéutica de la facticidad, Madrid: Alianza.

HEIDEGGER, Martin, SZ, Sein und Zeit. Tübingen, Niemeyer, 1963.

HEIDEGGER, Martin (1927). Ser y tiempo, trad. José Gaos. Buenos Aires: Fondo de Cultura Económica, 2019.

HEIDEGGER, Martin, GA 1, Frühe Schriften (1912-1916), ed. Friedrich-Wilhelm von Herrman. Frankfurt a. M.: Klostermann, 1978.

HEIDEGGER, Martin, GA 65, Phänomenologische Interpretationen zu Aristoteles. Einführung in die phänomenologische Forschung, eds. Walter Bröcker y Käte Bröcker-Oltmanns. Frankfurt a. M.: Klostermann, 1985.

KIERKEGAARD, Søren (1963). Los lirios del campo y las aves del cielo. Madrid: Guadarrama.

KIERKEGAARD, Søren (2008). La enfermedad mortal. Madrid: Trotta. 
KIERKEGAARD, Søren (2008). Postscriptum no cientifico y definitivo a Migajas filosóficas. México: Universidad Iberoamericana.

KIERKEGAARD, Søren (2016a). "El concepto de angustia", en CAPPELØRN; GONZALEZ; LARRAÑETA; TAJAFUERCE (eds.). Escritos, vol. 4/2. Madrid: Trotta, pp. 125-278.

KIERKEGAARD, Søren (2016b). "Migajas filosóficas o un poco de filosofía", en CAPPELØRN; GONZALEZ; LARRAÑETA; TAJAFUERCE (eds.). Escritos, vol. 4/2. Madrid: Trotta, pp. 25-124.

KIERKEGAARD, Søren (2007). "O lo uno o lo otro. Un fragmento de vida II", en CAPPELØRN; GONZALEZ; LARRAÑETA; TAJAFUERCE (eds.). Escritos, vol. 3. Madrid: Trotta, pp. 11-316.

KUDER, Paul (2015). Heideggers Kierkegaard. Dresden: Nomos.

PIEPER, Annemarie (2014). Søren Kierkegaard. München: Beck.

THONHAUSER, Gerhard (2016). “Ein rätselhaftes Zeichen. Zum Verhältnis von Martin Heidegger und Søren Kierkegaard", en SHULZ; STEWART; VERSTRYNGE (eds.). Kierkegaard Studies. Berlin: De Gruyter.

THONHAUSER, Gerhard (2011). Über das Konzept der Zeitlichkeit bei Søren Kierkegaard mit ständigem Hinblick auf Martin Heidegger. Freiburg/München: Alber.

RINGLEBEN, Joachim (1995). Die Krankheit zum Tode von Søren Kierkegaard. Erklärung und Kommentar. Göttingen: Vandenhoec. 